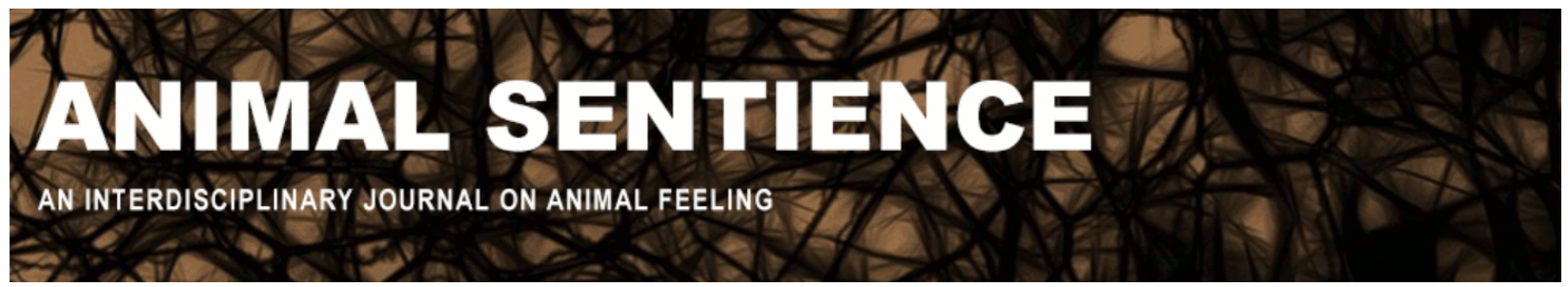

Rolle, M.E. (2016) Animal welfare and animal rights. Animal Sentience 5(8)

DOI: $10.51291 / 2377-7478.1001$

Date of submission: 2015-03-02

Date of acceptance: 2015-12-13

(c) (i)

This article has appeared in the journal Animal

Sentience, a peer-reviewed journal on animal

cognition and feeling. It has been made open access,

free for all, by WellBeing International and deposited

in the WBI Studies Repository. For more information,

please contact

wbisr-info@wellbeingintl.org.

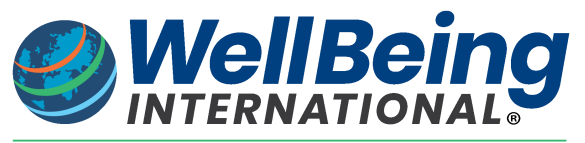

SOLUTIONS FOR PEOPLE, ANIMALS AND ENVIRONMENT 


\title{
Animal welfare and animal rights
}

Commentary on Broom on Animal Welfare

\author{
M. E. Rolle \\ Department of English, Linguistics \& Cultural Studies \\ University of Westminster
}

\begin{abstract}
This overview of Broom's book, Sentience and Animal Welfare (2014), considers the role the book could play in the animal rights debate. In a thoroughly researched and objectively presented text, Broom lays out information that could place doubt in the minds of decisionmakers. By highlighting not just the ways animals resemble humans, but also the ways humans resemble animals, Broom shines a light on a solidly grey area in the animal rights debate.
\end{abstract}

M. E. Rolle melliottr@hotmail.com decided to make a radical change after twelve years as a natural resources attorney for the federal government. She moved to England to undertake a master's degree in creative writing. Weaving animal rights themes into her writing, she is working on her first novel at the University of Westminster in London.

http://www.westminster.ac.uk/aboutus/faculties/humanities/departments/english

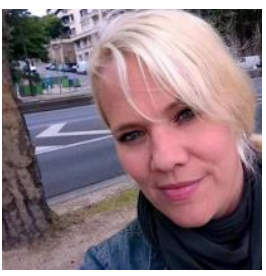

Broom's Sentience and Animal Welfare (2014) takes a compelling look at sentience: how it is defined - and can vary - across nonhuman animal and human populations, and the role it has played in recent years in the delineation of ethically appropriate animal treatment and protection. The book is at its heart a science text, with a solid historical overview and recent, thorough empirical support for the new positions described. While Broom makes suggestions about some of the specific issues discussed (e.g., that information like that presented in the book should be used to inform decision makers about animal sentience ahead of legislative or other action that could affect animal welfare), it is for the most part a presentation of information that withholds opinion.

In the book, Broom takes readers through a thorough review of the human understanding of sentience, both historically and at present. Broom also explains the complex structure and function of animal and human brains, and how sentience is not an independent output of the brain, but a combination of processes that include feelings and emotions, consciousness and awareness, and the ability of an individual to remember, learn, and have desires. Broom then further explains the way sentience develops in an individual, and how it can be affected over time by events such as injury and aging. Finally, Broom looks at the ways sentience has been, and perhaps should be, used in the delineation of ethically acceptable treatment and uses of animals. Broom also discusses the need for more coverage of the subject of sentience in veterinary and other animal-related education. 
Sentience has become an increasingly important factor in debates over how animals should be treated by humans. It has become a generally accepted belief in animal welfare theory that if an animal has the capacity to feel and perceive, then that animal also has the ability to suffer, and thus humans have a duty to eliminate or minimize the suffering of that animal when it is caused by their intervention. Some readers may be troubled at times by the objectivity with which Broom covers the important issues in the book. However, there is a real value in presenting issues related to sentience and animal welfare in an objective and scientifically defensible way. Such objective treatment could ultimately make the text more valuable in supporting arguments against the use of animals in general.

One particularly interesting aspect of the book is the way Broom considers sentience equally across species, analyzing nonhuman subjects alongside human ones. This juxtaposition highlights the fact that under certain conditions, humans can have lower cognitive and sentient functions than nonhuman animals. Given the historical tendency to look at mental capacity as a concrete basis for determining whether an animal deserves welfare protections, this universal analysis makes it harder to ignore the fact that there is a lot of grey area in this debate. Once this is more widely understood, it will likely become harder to defend the distinctions that have been drawn between animals and humans solely on the basis of mental capacity.

\section{References}

Broom, D. M. (2014). Sentience and Animal Welfare. Wallingford, Oxfordshire: CABI. 